\title{
A Behavioral Assessment of College Students' Knowledge, Awareness, and Consumption on Snack Foods That May Contain Probiotics
}

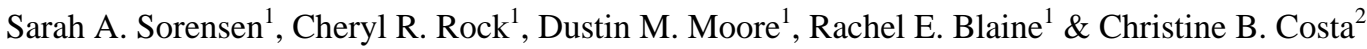 \\ ${ }^{1}$ Department of Family and Consumer Sciences, California State University, Long Beach, 90840, USA \\ ${ }^{2}$ Department of Nursing, California State University, Long Beach, 90840, USA \\ Correspondence: Dr. Cheryl Rock, 1250 Bellflower Boulevard, Long Beach, CA 90840, USA. Tel: \\ 562-985-4497. E-mail: cheryl.rock@ csulb.edu
}

Received: October 28, 2018 Accepted: November 15, 2018 Online Published: April 2, 2019

doi:10.5539/jfr.v8n3p16

URL: https://doi.org/10.5539/jfr.v8n3p16

\begin{abstract}
With the increasing variety of snack foods containing probiotics infiltrating the market, it is important that consumers become more aware and knowledgeable about these products. The aim of the current study was to investigate potential consumers' behavior by assessing knowledge about probiotics, awareness of snack foods containing probiotics, and frequently consumed snacks among student college departments within a university setting. Participants included 125 college students ( $n=34$ male, $n=91$ female), all 18 years and older, and evaluated via a 19-item questionnaire using descriptive statistics, one-way analysis of variance (ANOVA) and Gabriel's post hoc test. Level of significance was set at $p \leq 0.05$. There was a statistically significant difference in knowledge about probiotics among the student college departments, $p=0.012$. Specifically, students in the College of Health and Human Services (CHHS) were statistically significantly more knowledgeable than those in the Science, Technology, Engineering and Mathematics (STEM) college, $p=0.010$. There was no statistically significant difference in awareness of snack foods containing probiotics, $p=0.262$. On average, participants' knowledge about probiotics was low (48.1\%) and awareness of snack foods containing probiotics was very low (2.5\%), though, a majority of participants $(94.1 \%)$ were aware that yogurt may contain probiotics. Overall, these findings should guide food product developers and marketers to create products that are relevant and messages that enhance consumers' knowledge and awareness to the existence of the probiotics in that product.
\end{abstract}

Keywords: awareness, college students, knowledge, probiotics, snacks

\section{Introduction}

As a result of a shift in meal times and growing clinical evidence supporting the importance of probiotics, snacking and probiotic consumption have increased (Clarke, Black, Stussman, Barnes, \& Nahin, 2015; Douglas \& Sanders, 2008; Kant \& Graubard, 2015; Kumar, Vijayendra, \& Reddy, 2015; Piernas and Popkins, 2010). According to Piernas and Popkins (2010), there was a 26\% increase in snacking between the years 1977 and 2006. From 2007 to 2012, the use of probiotics and prebiotics had a fourfold increase with approximately 3 million more adults consuming probiotics (Clarke et al., 2015). To keep up with these demands, food product developers are investigating a number of innovative and novelty snack foods to be potential carriers for probiotics (Champagne, Gardner, \& Roy, 2005). In order for any food product to be classified as "probiotic" it must contain live microorganisms which, when administered in adequate amounts, confer a health benefit to the host (Lahtinen, 2012). Though not all the time, but often, fermented foods (primarily an anaerobic process [meaning that it happens without oxygen] in which microorganisms [e.g. bacteria or yeasts] convert sugars in food to other compounds like alcohol or organic acids, while also producing energy for themselves) serve as the main carriers for probiotics (Chilton, Burton, \& Reid, 2015; Stanton, Ross, Fitzgerald, \& Van Sinderen, 2005). While fermented dairy-based foods, including yogurts, kefir, and other cultured drinks, are the most common probiotic foods available, there is a growing demand for non-dairy alternatives (Champagne et al., 2005; Heller, 2001; Payahoo, Nikniaz, Mahdavi, \& 2012; Stanton et al., 2005). Non-dairy fermented foods that have been examined with respect to their potential in carrying probiotics include sauerkraut, pickles, fruit and vegetable juices, soy milk, pudding, chocolate, cereals, and dry sausages (Douglas \& Sanders, 2008; Kumar et al., 2015). Probiotics have been demonstrated to help with Clostridium difficile, onset and relapse of pouchitis, ulcerative colitis, bacterial vaginosis, oral cavity diseases and stimulation of the immune system (Derikx et al., 2016; 
Gionchetti et al., 2012; Goldenberg et al., 2017; Guillemard, Tondu, Lacoin, \& Schrezenmeir, 2010; Haukioja, 2010; Tachedjian, Aldunate, Bradshaw, \& Cone, 2017). These various health benefits, in addition to the research supporting probiotics strain stability and convenience, may help explain for the increase in probiotic consumption over the years (Champagne et al., 2005; Kumar et al., 2015).

According to literature (Al-Nabulsi et al., 2014; Stancak and Heuberger, 2009), although there is a wide range of probiotic choices commercially available, consumers may lack awareness and knowledge about probiotics. Awareness implies consciousness of something, while knowledge represents clear and certain mental apprehension (Rettie, 2003). In other words, a person can be aware of probiotics, but not know what they are, or vice versa (Christiansen \& Maglaughlin, 2003). One study found that more patients were familiar with the term "probiotics" (43\%) than they were knowledgeable about probiotics $(20 \%)$, such that they could correctly define the term from a list of responses (Betz, Uzueta, Rasmussen, Gregoire, Vanderwall, \& Witowich, 2015). And still, consumers have a difficult time identifying probiotic foods. When Stanczak and Heuberger (2009) asked participants to identify food sources that may contain probiotics (e.g., yogurt and milk), 54.6\% instead answered "don't know." Another study performed by Al-Nabulsi et al. (2014) found that a large number of participants (97.5\%) did not consume probiotics because they were "unaware" of what they are. While probiotic yogurt accounts for $78 \%$ of all probiotic sales worldwide, it is also considered as one of the most common foods that consumers associate with probiotics (Granato, Branco, Nazzaro, Cruz, \& Faria, 2010; Payahoo et al., 2012; Stancak and Heuberger, 2009). It is, therefore, important to further study consumers' extent of awareness and knowledge about probiotics, as it may unintentionally minimize consumers' options and sales among food product companies.

Furthermore, focusing on consumers' awareness and knowledge are two behavioral data points that link to behavioral segmentation which is essential in tailoring products to meet the needs of consumers (Fieldboom, 2018). Behavioral segmentation stems from marketing segmentation which allows companies to divide the market into groups or segments based on distinct needs or wants (Djokic, Salai, Kovac-Znidersic, Djokic, \& Tomic, 2013). By assessing a consumers' awareness to the existence of a product and knowledge of its full benefits, it will help determine what promotional materials and messaging are needed (Sunderland, 2017). And so, further research is needed to identify consumers' awareness toward snack foods that have been found to be potential carriers of probiotics and knowledge about probiotics. Additionally, identifying most frequently consumed snacks is a predictable assessment that allows researchers to keep up-to-date with commonly snacked foods and their positioning as a potential probiotic product. The current study will focus on college students, due to its convenience in sampling. The purpose was to better understand consumer behaviors to allow marketers to develop messages that enhance knowledge and awareness of probiotics which may ultimately optimize consumer options.

\section{Method}

\subsection{Hypothesis, Participant Characteristics, and Sampling Procedure}

The current study assessed students among college departments within a university setting by analyzing their knowledge about probiotics, evaluating their awareness of snack foods containing probiotics, and determining their top five frequently consumed snacks per week using a beverage and snack questionnaire (BSQ). The current study hypothesized that there would be no statistically significant difference in the target population's (i.e., student college departments) knowledge about probiotics, or awareness of snack foods containing probiotics.

Institutional Review Board (IRB) approval (1237262-2) was obtained prior to commencement of the study. Participants ( $n=34$ male, $n=91$ female) were recruited through snowball and convenience sampling and screened based on the inclusion criteria for their status as college students and at least 18 years of age. A multiple-choice questionnaire of 19-items was administered to eligible participants via version 2018 of Qualtrics. An informed consent was obtained from each participant and all participants were completely anonymous.

\subsection{Demographics and Knowledge about Probiotics}

The demographic questions included information about gender, age, ethnicity, education level, and college (i.e., arts, business administration, education, engineering, health and human services, liberal arts, natural sciences and mathematics, and continuing and professional education). To assess knowledge about probiotics, the participants were asked to answer nine multiple choice questions, plus an additional question on familiarity, addressing basic concepts of probiotics. 


\subsection{Awareness of Snack Foods Containing Probiotics}

To assess the participants' awareness of snack foods containing probiotics, they were asked to select how many visually represented snacks they believe may contain probiotics. There were eleven pictures in total of snack foods that have all been examined with respect to their potential in carrying probiotics (Douglas \& Sanders, 2008; Kumar et al., 2015). The included items were sauerkraut, chocolate, cereal, vegetable juice, fruit juice, pickles, yogurt, cheese, pudding, soy milk, dry sausages and one option listed as "none of the above."

\subsection{Beverage and Snack Questionnaire (BSQ)}

The BSQ was adapted from the Supplemental Nutrition Assistance Program Education (SNAP-ed) Evaluation Framework Interpretive Guide which the Fred Hutchinson Cancer Research Center (2010) developed; instruments were similar to those described by Cock et al. (2016). The BSQ assessed participants snack frequency with a reference period of one week. The six frequency categories were: never or less than one per week; one per week; two to four per week; five to six per week; one per day; two or more per day. The BSQ included a total of 35 beverage and food items which were selected according to the snack categories commonly illustrated on grocery store websites. The beverage items included the following: fruit and vegetable juices, carbonated beverages, coffee, hot tea, iced tea, drinks such as energy, sports, powdered mixes, milk substitutes, dairy, smoothies, hot cocoa as well as cocktails, beer/wine/spirits. Snack food items included the following: chips, nuts/trail mixes, cookies, crackers, popcorn, dips/spreads, granola bars/snack bars, dried meats, fruit snacks, pretzels, dried fruit/dried vegetables, pudding/gelatin, yogurt, fruit cups/fruit sauces, rice cakes, snack cakes, gums/mints, candies, chocolate and ice cream.

\subsection{Questionnaire Validity}

Prior to distribution of the questionnaire, an expert panel of credentialed faculty members reviewed the survey items and provided feedback. Good internal validity was demonstrated by the expert panel results.

\subsection{Data Analysis}

Data from the current study was analyzed using the International Business Machine (IBM) Statistical Package for the Social Sciences (SPSS), Version 24. Descriptive statistics (i.e., frequency and mean scores) were used to analyze all variables for demographic data, frequency of consumed snacks, knowledge about probiotics, and awareness of snack foods containing probiotics. One-way analysis of variance (ANOVA) was used to determine whether there were any statistically significant differences $(p \leq 0.05)$ among the student college departments, age (18-50 years old), and ethnicity regarding knowledge about probiotics and awareness of snack foods containing probiotics. The Gabriel's post-hoc test was used to confirm exactly which student college department had significant differences. The independent samples $t$-test was used to determine whether there was a statistically significant difference $(p \leq 0.05)$ between the means in gender and degree level on knowledge about probiotics and awareness of snack foods containing probiotics.

\section{Results and Discussion}

\subsection{General Demographic Characteristics of the Study Population}

In the current study, participants were recruited between the months of June and July in the year of 2018 from several college departments within a university setting and was based on convenience sampling. Specifically, the participants $(n=125)$ were college students, mainly undergraduates $(79.0 \%)$ as presented in Figure 1 , and predominantly female (Figure 2). Age groups of the participants ranged from 18-50 years old, with most of them being between the 21-24 years old range (Figure 3). With regards to their ethnicity, most of the participants were Hispanic/Latino (31.2\%) followed by White American/Caucasian (28.0\%), Asian/Native Hawaiian/Pacific Islander (25.6\%), African American/African/Black/Caribbean (8.0\%), and other (7.2\%). Participants were originally surveyed and categorized according to their college department (Figure 4). In order to appropriately perform statistical analysis, the categories were repositioned so that population size was more equally distributed across all categories. The college departments that were smaller in numbers were combined into categories of similar college departments, while larger college departments were able to remain as their own category. In brief, the revised college department categories consisted of 32.8\% College of Health and Human Services (CHHS), 24.8\% Science, Technology, Engineering and Mathematics (STEM) fields which amalgamated the following college departments: College of Engineering (COE) and College of Natural Sciences and Mathematics (CNSM), 24.8\% College of Liberal Arts (CLA), and 17.6\% non-science (College of the Arts [COTA], College of Business Administration [CBA], and College of Education [CED]). 


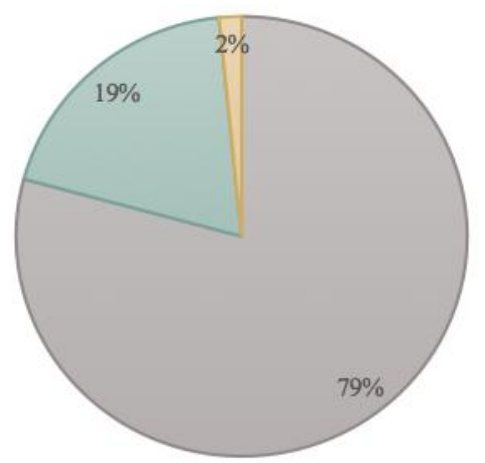

घ Undergraduate student $\square$ Graduate student $\square$ Other

Figure 1. Demographic characteristics of students' degree level

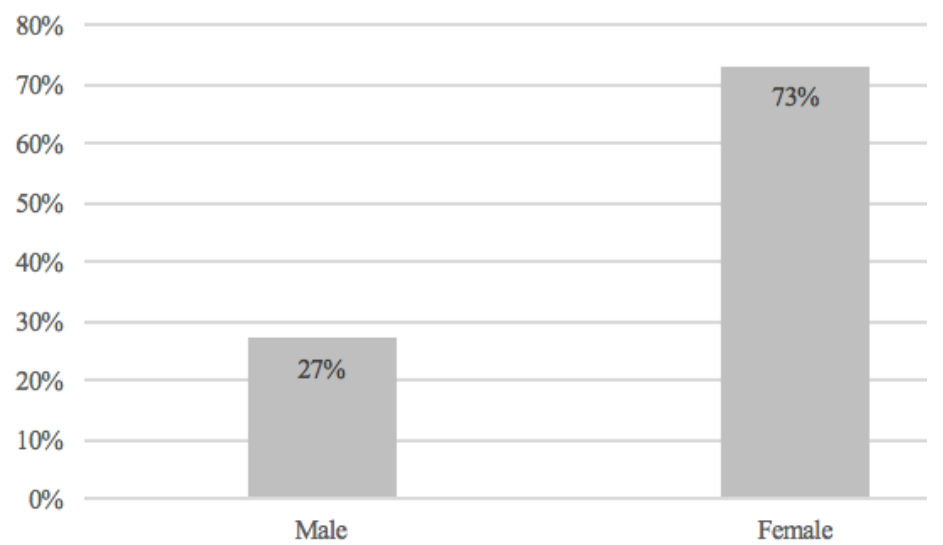

Figure 2. Demographic characteristics of students' gender

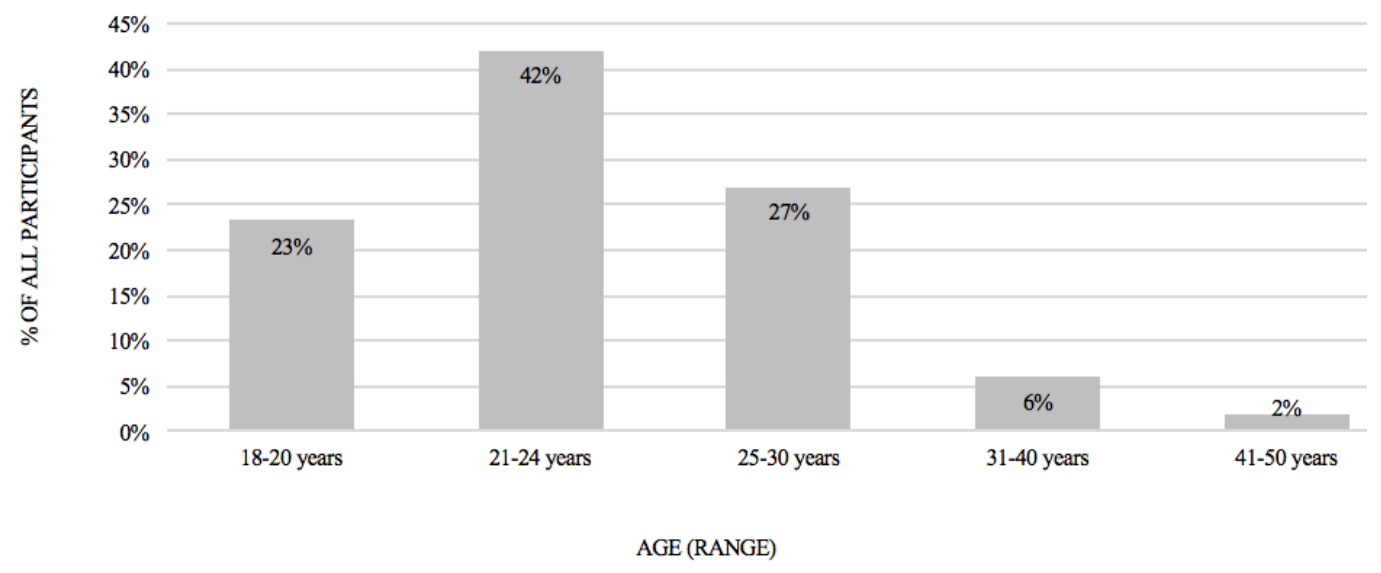

Figure 3. Demographic characteristics of students' age ranges from 18-50 years' old 


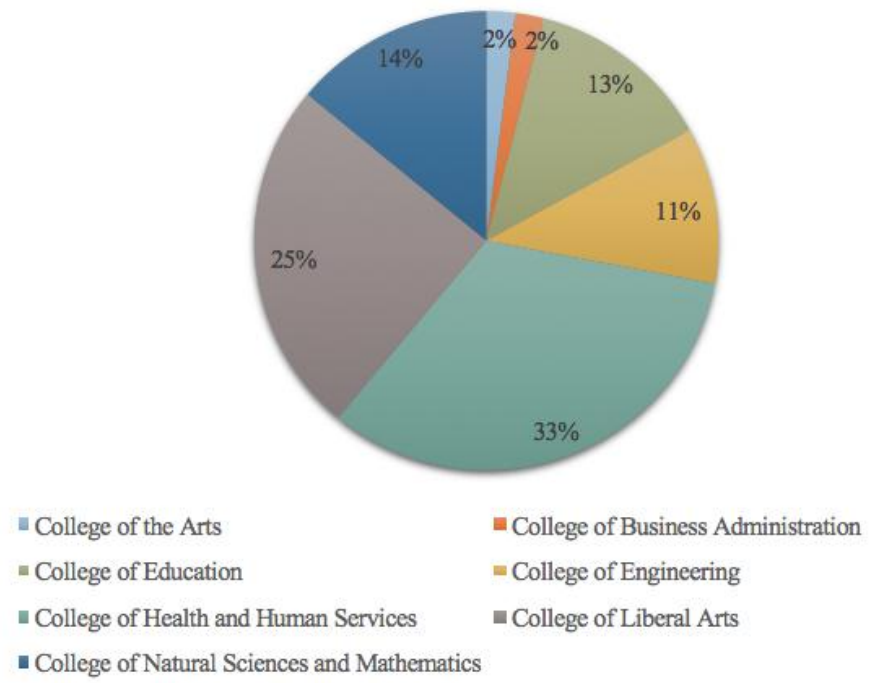

Figure 4. Demographic characteristics of students' college department categories

\subsection{Knowledge about Probiotics}

There was a statistically significant difference in knowledge about probiotics on the different college departments, $p=0.012$. More specifically, Gabriel's post-hoc analyses revealed that CHHS students were statistically significantly $(p=0.010)$ more knowledgeable about probiotics than students in STEM. A similar trend was observed in the study by Al-Nabulsi et al. (2014) in which probiotic knowledge was significantly influenced by the students' study major and particularly higher among health science students compared to those in basic sciences, engineering and others. Payahoo et al. (2012) also found significant differences across majors, in which pharmacy and nutrition reported a higher level of knowledge than other majors. These differences in knowledge about probiotics across the college departments reject the null hypothesis, and may be due to the differences in curriculum and exposure to updated nutritional findings from faculty as well as colleagues.

While there were no statistically significant differences $(p=0.616)$ between ethnicity on the students' knowledge about probiotics, there was a significant difference found among the age ranges $(p=0.006)$. To illustrate, Gabriel's post-hoc analyses revealed that 25-30 year olds were statistically significantly $(p=0.033)$ more knowledgeable about probiotics than 21-24 year olds. Another statistically significant effect was found in degree level ( $p=0.006, r=0.25$; Pearson's correlation is denoted by $r$ in which $0.10-0.29$ indicates a small effect), in which graduate students scored higher on knowledge about probiotics than undergraduate students. It could be implied that differences in educational levels may be related to additional courses taken by graduate students and not undergraduate students. There was also a statistically significant effect of gender $(p=0.035, r=0.13$; indicating a small effect), by which females scored higher on knowledge about probiotics than males. Furthermore, the effect size indicated that beyond statistical significance, there was a meaningful difference between knowledge about probiotics on degree level and gender. Al-Nabulsi et al. (2014) similarly found a significant difference in knowledge about probiotics and gender, by which female students' knowledge was better than male students; yet, did not find a statistically significant difference $(p=0.784)$ between knowledge about probiotics and educational level. The differences between gender may be related to the differences in perception of healthiness and willingness to try functional foods (Ares \& Gambara, 2007). Ares and Gambaro (2007)) further found that women were able to perceive healthiness better than men when considering concepts about functional foods, such as probiotic yogurt.

Moreover, it was observed that the majority of participants correctly defined the term probiotics (96.8\%) and its health benefit (84.0\%) (Figure 6). Yet surprisingly, only 69.6\% were able to accurately identify probiotic food sources. It was also observed that students were less knowledgeable about probiotic questions that were more specific. This may imply that consumers are least likely to choose a food containing probiotics, despite their ability to define the term. For this reason, it is important for food product developers to create transparent messages and clearly label food products if probiotics are present in them. This is especially important for novel or non-dairy products in which consumers would not expect probiotics to exist in. 


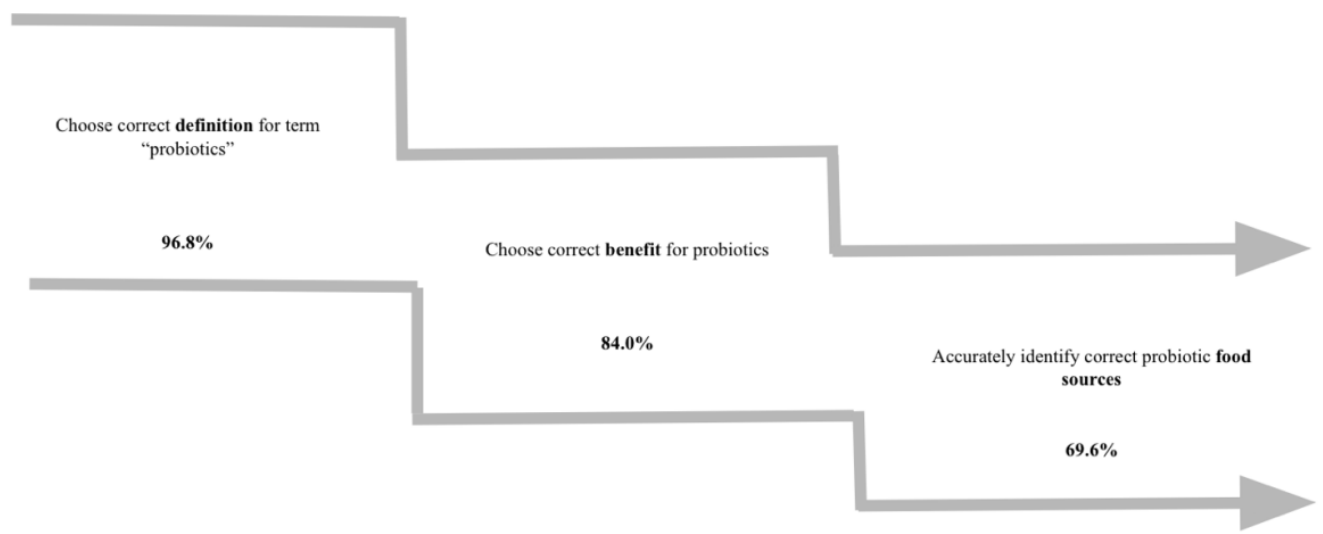

Figure 5. The correct response (\%) for each question on knowledge about probiotics

When comparing the current study results to other studies, differences were found. To illustrate, participants sampled from the general public, were less able to identify the term probiotics $(43.7 \%)$ compared to the current study that sampled students (96.8\%) (Stanczak \& Hueberger, 2009). This difference may be environmental (i.e. students vs. non-students) in which the participants from the study, being students, may have been more up-to-date on research and informed about certain topics related to probiotics. Meanwhile, when comparing the current study to student-based studies, there were contrasting results. The high percentage (96.8\%) of those that correctly defined the term probiotics in the current study was similarly high among medical science students (83\%), yet drastically lower among other college students (7.0\%) (Al-Nabulsi et al., 2014; Payahoo et al., 2012). This may be due to differences in questions used and other influencing factors such as level of degree.

\subsection{Awareness of Snack Foods Containing Probiotics}

In the current study, there was no statistically significant effect of the different college departments on awareness of snack foods containing probiotics $(p=0.262)$, which failed to reject the null hypothesis. There were no statistically significant differences in age range $(p=0.097)$, ethnicity $(p=0.067)$, degree level $(p=0.077)$ or gender $(p=0.144)$ on awareness of snack foods containing probiotics. Gender, however, did represent a small-sized effect $(r=0.13)$, indicating a type II error (also known as a "false finding") as there seems to be a meaningful difference in awareness between genders. In contrast, Al-Nabulsi et al. (2014) found a statistically significant difference in awareness between genders, in which females were significantly more able than males to correctly identify yogurt $(p=0.033)$ and milk $(p=0.044)$ as commonly available forms of probiotic products. Briefly, experimental data showed that participants were most aware of yogurt (94.4\%) containing probiotics, followed by cheese, soy milk, sauerkraut, vegetable juice, pickles/pudding/fruit juice, chocolate, cereal, and dry sausages (Figure 7). These results are consistent with a study by Payahoo et al. (2012) in which most of the students $(72.9 \%)$ reported yogurt and other dairy products as commonly available sources of probiotics. Interestingly, Al-Nabulsi et al. (2014) found that college students who were aware of probiotics obtained their information mostly from college courses, followed by television commercials, television programs, healthcare providers and magazines or newspapers. This may emphasize that college students may be more likely to be aware of foods containing probiotics than the general public considering school was considered the main source of information. 

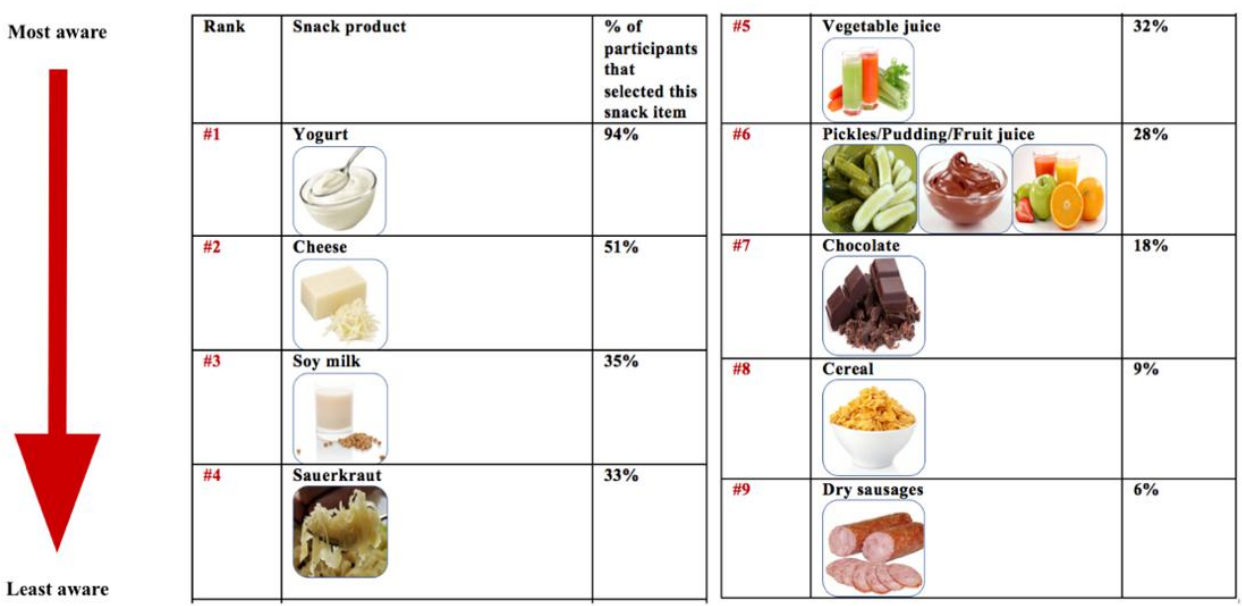

Figure 6. Awareness of snack foods containing probiotics ranked in order from most to least aware

\subsection{General Knowledge about Probiotics and Awareness of Snack Foods Containing Probiotics and Familiarity}

Overall, the experimental data indicated that there was a lack of knowledge about probiotics and awareness of snack foods containing probiotics among college students. Out of all the questions assessing their knowledge, on average, students answered $48.1 \%$ of the questions correctly. In relation to questions of awareness, on average, students only answered $2.5 \%$ of the options provided on snack foods containing probiotics. Both awareness and knowledge scores were low and demonstrate the need for educating and developing marketing tactics to raise knowledge and awareness. Furthermore, most respondents were "somewhat familiar" (40.8\%) followed by those that were "familiar" (34.5\%), "very familiar" (12.8\%), "extremely familiar" (10.4\%), and "not familiar" (1.5\%). Those that were "not familiar" was defined as not having heard of the term probiotics before. This percentage was very small compared to another study who found $32.9 \%$ of participants that had not heard of the term probiotics before (Chin-Lee, Curry, Fetterman, Graybill, \& Karpa, 2014). This may be due to differences in level of education, by which all of the current study participants were current college students compared to those that had varied levels of education, some not having obtained a high school diploma/GED (25.6\%).

\subsection{Beverage and Snack Questionnaire (BSQ) per Week}

From the data analysis, it was observed that the five most frequently consumed snack foods using the BSQ per week were nuts $(73.6 \%)$, > coffee $(70.4 \%)$, > dairy $(69.6 \%)>$ granola $(66.4 \%)$, > chips $(60.8 \%)$ (Figure 5). The popularity of salty snacks, including nuts and chips, can be supported by other research. To illustrate, Piernas and Popkins (2010) showed that between 1977 and 2006, there was an increased intake in salty snacks, chips, and nuts. In 2014, salty snacks (i.e. nuts, chips, popcorn, and crackers) were also found to be ranked the top category of snack foods (Bartelme, 2016). This may be related to consumers valuing the taste of salty snacks more than their nutrition (Mintel, 2015). It is interesting to note how snacking selections have changed over time. In contrast, in 1980, Khan did not find nuts to be a common snack among college students, and that fruit was a most common snack. Yet, Piernas and Popkins (2010) research showed that intake of nuts had increased, while other snacks such as fruit have slightly declined since 1977. The results from past research and the current study demonstrates the importance of keeping up-to-date on research and assessing consumers' behavior in relation to the positioning and marketing of snack foods, especially those with added benefits such as probiotics. Snacking selections may also differ from region to region, as in the example of fruit being the most common snack in Brazil, despite its decline in the U.S (Duffey, Rivera, \& Popkin, 2014). 


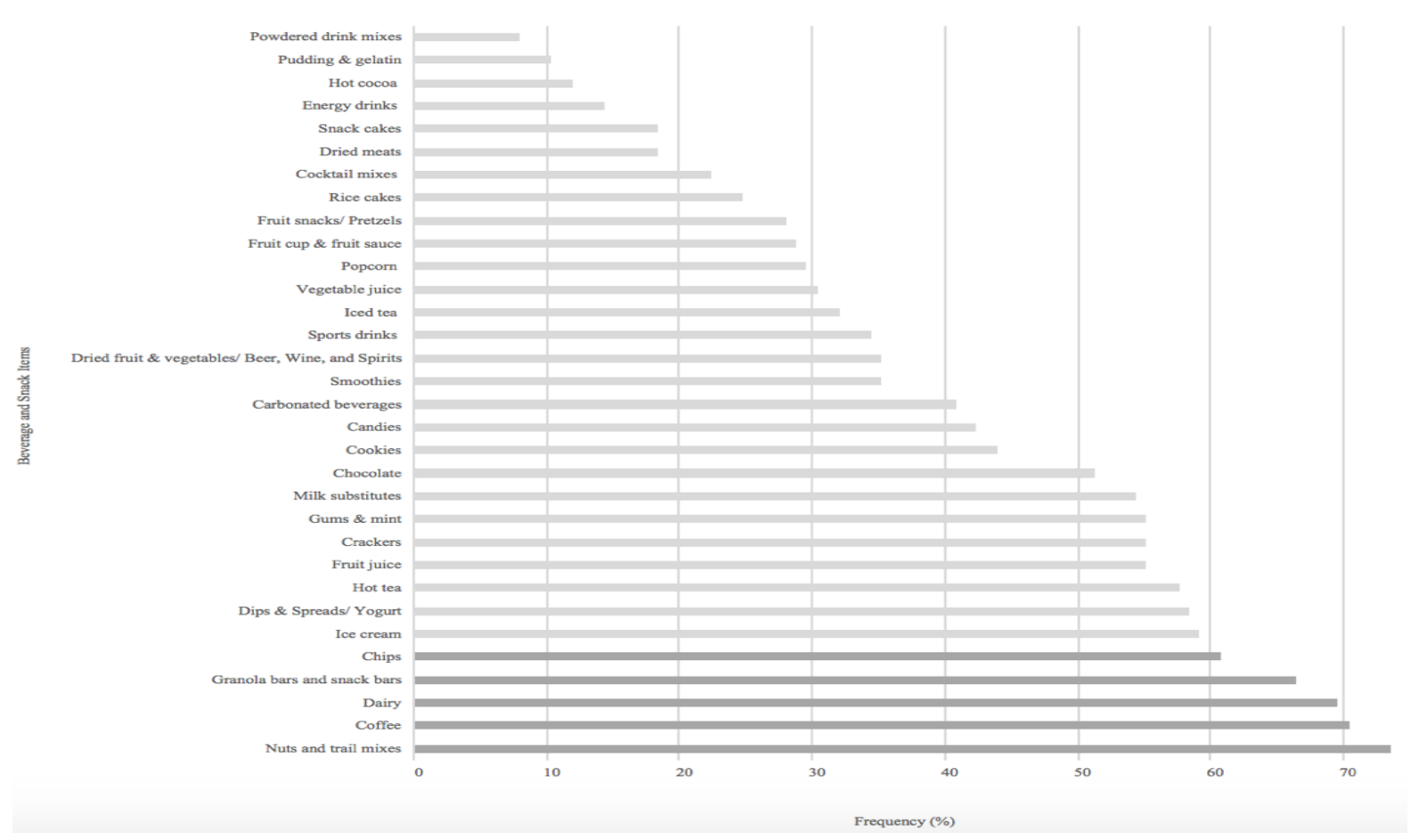

Figure 7. Most frequently consumed beverages and snacks (bottom to top)

\subsection{Limitations}

It is important to consider the limitations of the current study since the sample size was small and not representative of the entire college student population or general public. This may limit the analysis of students' current knowledge and awareness, compared to using a greater and more diverse sample. Using the BSQ was another limitation, as it relies on the participant's memory rather than the actual frequency intake. Also, the questionnaire was not tested for reliability which is important for internal consistency.

\subsection{Future Recommendations}

As researchers continue to study which foods may source probiotics, nuts and other frequently consumed snacks could be the focus according to the experimental results of the current study. It also supports the idea of behavioral segmentation, in which food product developers create innovative items based on the studied consumer behaviors. In relation to differences in knowledge about probiotics, an adjustment in curriculum or increase in the number of basic food science and nutrition courses offered may increase and balance the level of knowledge among students within various college departments. To help increase awareness of snack foods containing probiotics, marketing may focus on enhancing recognition by utilizing advertisements, public relations, and promotion to increase the impact and knowledge about probiotics. In conclusion, the results of the current study may help food product developers and marketers create messages that are relevant and will resonate with the consumer to increase the impact of their product in terms of potential health benefits.

\section{References}

Ares, G., \& Gámbaro, A. (2007). Influence of gender, age and motives underlying food choice on perceived healthiness and willingness to try functional foods. Appetite, 49(1), 148-158. https://doi.org/10.1016/j.appet.2007.01.006

Al-Nabulsi, A. A., Obiedat, B., Ali, R., Osaili, T. M., Bawadi, H., Abushelaibi, A., ... Holley, R. A. (2014). Knowledge of probiotics and factors affecting their consumption by Jordanian college students. International Journal of Probiotics \& Prebiotics, 9(3), 77-86.

Bartelme, M. Z. (2016). Consumers get serious about snacking. Food Technology, 70(5), 31-45.

Betz, M., Uzueta, A., Rasmussen, H., Gregoire, M., Vanderwall, C., \& Witowich, G. (2015). Knowledge, use and perceptions of probiotics and prebiotics in hospitalised patients. Nutrition \& Dietetics, 72(3), 261-266. 
https://doi.org/10.1111/1747-0080.12177

Champagne, C. P., Gardner, N. J., \& Roy, D. (2005). Challenges in the addition of probiotic cultures to foods. Critical Reviews in Food Science and Nutrition, 45(1), 61-84. https://doi.org/10.1080/10408690590900144

Chilton, S., Burton, J., \& Reid, G. (2015). Inclusion of fermented foods in food guides around the world. Nutrients, 7(1), 390-404. https://doi.org/10.3390/nu7010390

Chin-Lee, B., Curry, W. J., Fetterman, J., Graybill, M. A., \& Karpa, K. (2014). Patient experience and use of probiotics in community-based health care settings. Patient Preference and Adherence, 8, 1513. https://doi.org/10.2147/PPA.S72276

Christiansen, N., \& Maglaughlin, K. (2003). Crossing from physical workplace to virtual workspace: Be aware! In Human-Computer Interaction: Theory and Practice, (part 1). Volume 1 of the Proceedings of HCI International 2003, 10th International Conference on Human - Computer Interaction Symposium on Human Interface (Japan) 2003 5th International Conference Engineering Psychology and Cognitive Ergonomics 2nd International Conference on Universal Access in Human- Computer Interaction 22 -27 June 2003, Crete, Greece (pp. 1128-1132). Mahwah, NJ: Lawrence Erlbaum.

Clarke, T. C., Black, L. I., Stussman, B. J., Barnes, P. M., \& Nahin, R. L. (2015). Trends in the use of complementary health approaches among adults: United States, 2002-2012 (No. 79). National health statistics reports.

Derikx, L. A., Dieleman, L. A., \& Hoentjen, F. (2016). Probiotics and prebiotics in ulcerative colitis. Best Practice \& Research Clinical Gastroenterology, 30(1), 55-71. https://doi.org/10.1016/j.bpg.2016.02.005

Djokic, N., Salai, S., Kovac-Znidersic, R., Djokic, I., \& Tomic, G. (2013). The use of conjoint and cluster analysis for preference-based market segmentation. Engineering Economics, 24(4), 343-355. https://doi.org/10.5755/j01.ee. 24.4.3118

Douglas, L. C., \& Sanders, M. E. (2008). Probiotics and prebiotics in dietetics practice. Journal of the American Dietetic Association, 108(3), 510-521. https://doi.org/10.1016/j.jada.2007.12.009

Duffey, K. J., Rivera, J. A., \& Popkin, B. M. (2014). Snacking is prevalent in Mexico-3. The Journal of Nutrition, 144(11), 1843-1849. https://doi.org/10.3945/jn.114.198192.

Fieldboom. (2018). Behavioral Segmentation - Definition, examples \& case studies. Retrieved from https://www.fieldboom.com/behavioral-segmentation

Fred Hutchinson Cancer Research Center. (2010). Beverage and Snack Questionnaire. Retrieved from https://snaped.fns.usda.gov/materials/beverage-and-snack-questionnaires-bsq

Gionchetti, P., Calafiore, A., Riso, D., Liguori, G., Calabrese, C., Vitali, G., ... Rizzello, F. (2012). The role of antibiotics and probiotics in pouchitis. Annals of Gastroenterology, 25(2), 100.

Goldenberg, J. Z., Yap, C., Lytvyn, L., Lo, C. K. F., Beardsley, J., Mertz, D., ... Johnston, B. C. (2017). Probiotics for the prevention of Clostridium difficile-associated diarrhea in adults and children. Cochrane Database of Systematic Reviews, 2017(12). https://doi.org/10.1002/14651858.CD006095

Granato, D., Branco, G. F., Nazzaro, F., Cruz, A. G., \& Faria, J. A. (2010). Functional foods and nondairy probiotic food development: Trends, concepts, and products. Comprehensive Reviews in Food Science and Food Safety, 9(3), 292-302. https://doi.org/10.1111/j.1541-4337.2010.00110.x

Guillemard, E., Tondu, F., Lacoin, F., \& Schrezenmeir, J. (2010). Consumption of a fermented dairy product containing the probiotic Lactobacillus casei DN-114 001 reduces the duration of respiratory infections in the elderly in a randomised controlled trial. British Journal of Nutrition, 103(1), 58-68. https://doi.org/10.1017/S0007114509991395

Haukioja, A. (2010). Probiotics and oral health. European Journal of Dentistry, 4(3), 348-355.

Heller, K. J. (2001). Probiotic bacteria in fermented foods: Product characteristics and starter organisms. The American Journal of Clinical Nutrition, 73(2), 374s-379s. https://doi.org/10.1093/ajcn/73.2.374s.

Kant, A. K., \& Graubard, B. I. (2015). 40-year trends in meal and snack eating behaviors of American adults. Journal of the Academy of Nutrition and Dietetics, 115(1), 50-63. https://doi.org/10.1016/j.jand.2014.06.354

Khan, M. A. (1980). Research food snacking among college students. Journal of Foodservice, 1(1), 1-8. https://doi.org/10.1111/j.1745-4506.1980.tb00240.x

Kumar, B. V., Vijayendra, S. V. N., \& Reddy, O. V. S. (2015). Trends in dairy and non-dairy probiotic products-a 
review. Journal of food science and technology, 52(10), 6112-6124.

Mintel. (2015). Chips, Pretzels and Corn Snacks. Retrieved from http://academic.mintel.com/display/590143

Lahtinen, S. J. (2012). Probiotic viability-does it matter? Microbial Ecology in Health and Disease, 23(1), 18567-18572.

Payahoo, L., Nikniaz, Z., Mahdavi, R., \& Abadi, M. A. J. (2012). Perceptions of medical sciences students towards probiotics. Health Promotion Perspectives, 2(1), 96. https://doi.org/10.5681/hpp.2012.012

Piernas, C., \& Popkin, B. M. (2010). Snacking increased among US adults between 1977 and 2006-3. The Journal of Nutrition, 140(2), 325-332. https://doi.org/10.3945/jn.109.112763

Rettie, R. (2003). Connectedness, awareness and social presence. Retrieved from http://eprints.kingston.ac.uk/2106/1/Rettie.pdf

Stanczak, M., \& Heuberger, R. (2009). Assessment of the knowledge and beliefs regarding probiotic use. American Journal of Health Education, 40(4), 207-211. https://doi.org/10.1080/19325037.2009.10599095

Stanton, C., Ross, R. P., Fitzgerald, G. F., \& Van Sinderen, D. (2005). Fermented functional foods based on probiotics and their biogenic metabolites. Current opinion in biotechnology, 16(2), 198-203. https://doi.org/10.1016/j.copbio.2005.02.008

Sunderland, S. (2017). What is behavioral segmentation and why should you use it? Retrieved from http://www.swiftlocalsolutions.com/blog/what-is-behavioral-segmentation-and-why-should-you-use-it

Tachedjian, G., Aldunate, M., Bradshaw, C. S., \& Cone, R. A. (2017). The role of lactic acid production by probiotic Lactobacillus species in vaginal health. Research in Microbiology, 168(9-10), 782-792. https://doi.org/10.1016/j.resmic.2017.04.001

\section{Copyrights}

Copyright for this article is retained by the author(s), with first publication rights granted to the journal.

This is an open-access article distributed under the terms and conditions of the Creative Commons Attribution license (http://creativecommons.org/licenses/by/4.0/). 